\title{
Incremental Planning The Value of Incremental Development in City Growth and Clarification of the Organic
}

\author{
David GREEN, Perkins\&Will, USA
}

\begin{abstract}
We often find ourselves wandering through the older parts of cities and understand that these places are generally walkable, diverse, and varied. We experience these observations directly as we engage with our physical surroundings. These wanderings seem to generally elicit the same question; "Why can't we make places like this today?". This is not a question of historic character, authenticity, preservation, or materiality. It is, rather, a question of the process of subdivision and the actions through which these cities have been developed. The one consistent characteristic, common to all these areas, is that they were developed incrementally, over time, evolving with each addition in the absence of a strong, centralized projection of use distribution. Varied uses emerged in seemingly haphazard patterns.

The incremental development process is possible in both highly planned as well as more loosely planned cities. Manhattan is simultaneously one of the most rigidly planned cities as well as one of the clearest examples of incremental development over the past two hundred years. Paris is another example of a city borne of incremental development; however, it grew without a clear, centralized plan. Instead, it developed on the margins, with many smaller, individual decisions about its form and growth, with the basic unit of development the individual, parcel of subdivision. Manhattan is compositionally orthogonal, and Paris is compositionally organic. However, both are operationally organic, meaning the individual projects were developed in the absence a rigid, use-based system that projected zones and parcels of particular uses.

It is possible to build cities that are walkable, diverse, and varied, and further, that are adaptable and sustainable, but only if we understand the fundamental structure that led to the outcomes of cities that emerged in pre-regulatory periods and those planned and developed in the post-regulatory, zoning and landuse prioritized, era; the era in which we find ourselves currently.
\end{abstract}

\section{Keywords}

Incremental, Subdivision, Land-Use, Organic, Adaptability, Walkability

\section{Incremental Cities}

\subsection{Overview}

In famous destinations such as the Marais in Paris or Bloomsbury in London, or sometimes less wellknown like the Fatih District in Istanbul or the French Concession in Shanghai, we find ourselves wandering through and wondering to ourselves why it seems impossible to develop these types of places in today's world. Wherever it may be, these places are generally walkable, diverse, varied, and engaging. And they seem always to elicit this same question, "Why not today?". Of course, there are myriad reasons why places like these, created in eras of pre-regulatory conventions, remain elusive to us, as we 
address the current planning and design of cities. It is necessary to understand which traits are shared across these urban areas to address this question.

Enchanting urban spaces that are walkable, beautiful, and vibrant exist throughout the world in many different forms, densities, styles, and varying states of rehabilitation. However, the one consistent

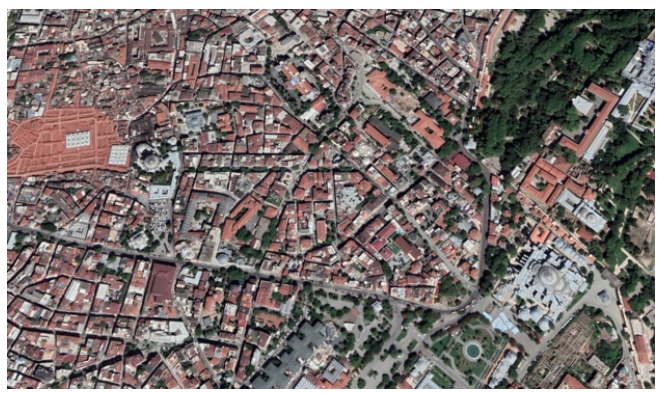

Figure 4 Fatih, Istanbul Aerial. Source: Google Earth, earth.google.com/web/

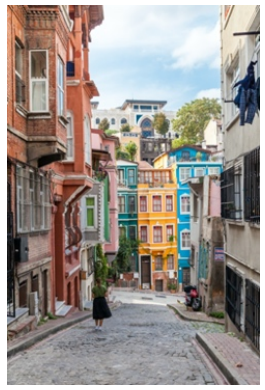

Figure 3 Fatih Building Fabric (WAF, 2020) characteristic common to all these areas is that they were developed incrementally, over time, evolving with each addition. The additions can vary in size and frequency and be more, or less, consecutive, but the basic characteristic shared throughout is that city growth occurs through the completion of small projects. These projects are further positioned within a series

of small, individual parcels that represent the fundamental subdivision of the city, the physical layout of both the public and private realms. Historically, whether more regular in pattern, as with the Roman

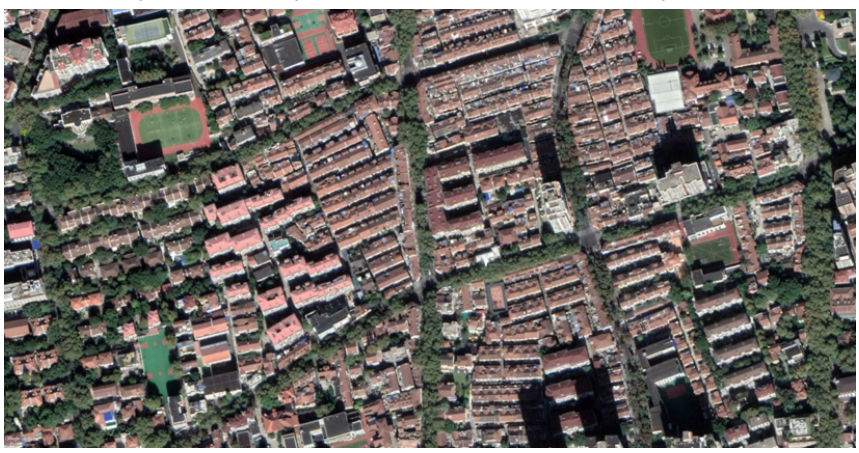

Figure 1 Shanghai French Concession Aerial. Source: Google Earth, earth.google.com/web/

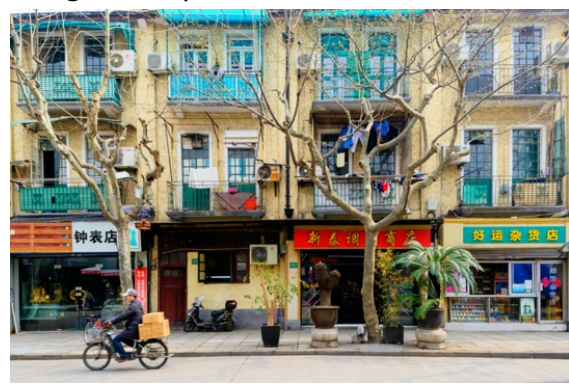

Figure 2 Shanghai French Concession Building Fabric (WAF, 2020)

town, or less consistent as seen in the Medieval city, the foundation of the planning process is always the process of subdividing land. In either instance, the increment of development-the subdivided parcelwas small. This seemingly arbitrary growth was true regardless of a centrally derived town plan or a city that grew by planning on the margins.

\section{The Organic}

\subsection{Understanding Organic}

Organic: having the characteristics of an organism: developing in the manner of a living plant or animal. This is the typical definition used by planners and urban designers to explain organic growth or organic development patterns. This is an inherently flawed understanding of the process through which cities are planned and developed, and it has resulted in two challenges in understanding past and current city development.

The first is the sense that organic is defined as 'not orthogonal', and this has led to the colloquial use of the word 'organic' to describe development patterns that are curvilinear or generally perceived to be irregular. This is evidenced in numerous academic and technical papers that address, in particular, the street patterns of cities. It has further led to an interpretation that cities developed incrementally and cities that developed in an 'organic' manner are the same. However, the development process, the 
operational subdivision of cities, is entirely distinct from the form the city takes. There are developments that are curvilinear, yet highly planned, including most American suburbs. There is nothing about the form of development patterns that is inherently organic, except as it is understood as a generic descriptor of irregularity, which offers no value the understanding of the development process.

The second is the resulting conclusion that irregular cities are not planned. In fact, all cities are planned. The degree to which they are planned through a central authority or planned on the margins is key to understanding the relationship between the planning process and the form of the resulting city. No one would disagree that San Francisco was a planned city, however many would say medieval Paris was not a planned city, that it was 'organic'. It was planned, but it was planned through a multitude of small decisions made on the margins. The city grew incrementally in form as well as in use.

The idea of the incremental city and the organic can be defined as:

Operationally Organic (Incremental): cities that have developed projects and uses in the absence of a central regulatory authority that projects land-uses across zones of a city.

Compositionally Organic: cities that are irregular in form related to development patterns.

Manhattan is much more operationally organic than a typical American suburb, while the American suburb is compositionally organic, and Manhattan is not. In the development of cities, the operationally organic/incremental growth process is critical to making diverse, varied, interesting, adaptable places, while the compositionally organic is not.

In many cases, the idea of incremental growth is referred to as an organic progression. While wandering through Marrakech, for example, one isn't thinking about the small, marginal, and gradual planning process that drove the city to its current form. Instead, the mind contemplates the irregular pattern of the inviting "organic" streets. This perception is a misapprehension in which organic composition comprises forms that are not regular or orthogonal, thereby clouding the actual underlying characteristic of the city's development. That is, the seeming randomness of the city's development pattern isn't the result of its level of incremental development. Instead, it reflects the type of incremental development. It is a city developed in the absence of a projected, planned public framework.

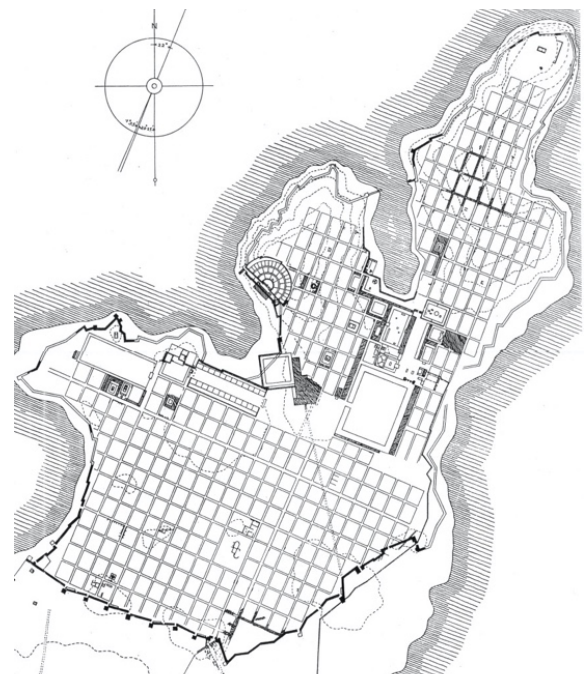

Figure 6 Plan of Miletus, (Magli, 2007)
Whether a city possesses a proposed public framework as with Hippodamus' Miletus, or it does not, as in the case of Chinon's historic center, neither is indicative of the level of incremental development intrinsic to expansion. New York

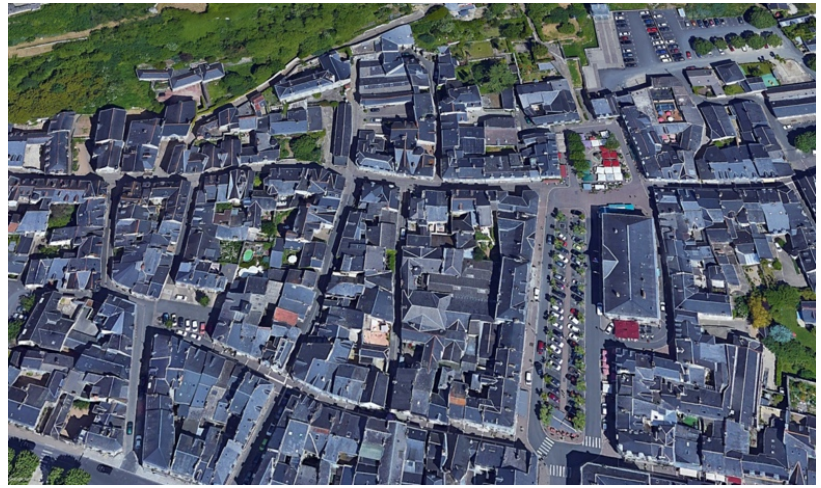

Figure 5 Chinon Aerial. Source: Google Earch, earth.google.com/web/

and its gridiron framework, a series of rectilinear forms, buildings, and orthogonal streets, reflects a prime example of this sort of progression. Its structure is not perceived as incremental by virtue of the projected plan with its generally straight lines and right angles. And it is certainly not commonly referred 
to as organic. However, development happened in a primarily incremental manner, and in many ways, organically, although operationally organic, not compositionally organic. The city grew through many small changes. Along with New York, Paris and London also offer prime examples of this concept.

\section{Planning as Subdivision}

\subsection{Projected Plan vs. Incremental Plan}

New York is a rational, gridiron plan. Paris is a series of generally straight streets that aren't parallel. London is a series of not-so-straight streets that are rarely parallel. In the compositional sense of the

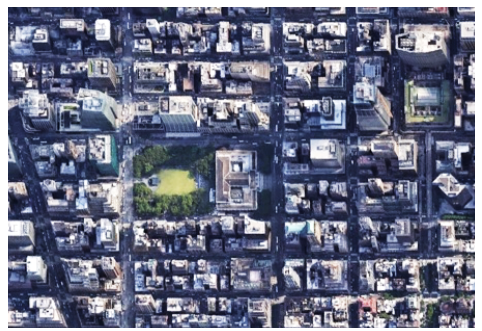

Figure 9 New York Aerial. Source: Google Earth, earth.google.com/web/

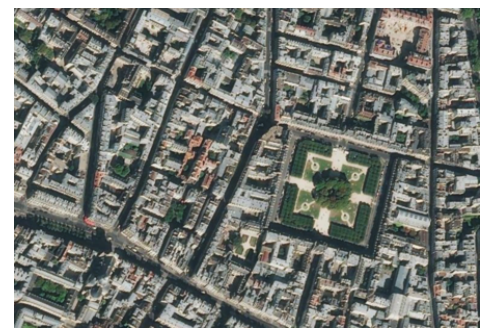

Figure 8 Paris Aerial. Source: Google Earth, earth.google.com/web/

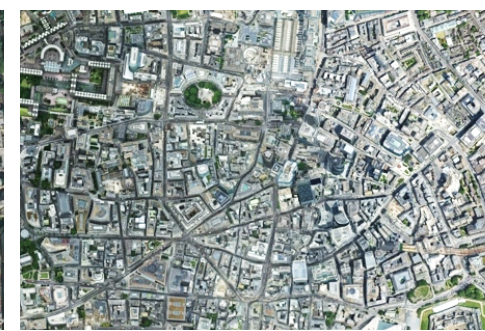

Figure 7 London Aerial. Source: Google Earth, earth.google.com/web/

word, organic somehow equals irregularity of form. By this assessment, it is probably accurate to say New York is the least and London the most organic of the three examples. But in the operational sense of the word, organic represents an incremental process of development over time, with many small projects developed individually. In this operative way, New York, Paris, and London are all generally equal in terms of the incremental growth levels that produced each city. They have all evolved over time, with little in the way of planned-use distribution or zoning, except the parts retroactively placed as overlays. There are all sorts of different projects and buildings, with different uses, styles, heights, densities, and so forth, each distributed in a very diverse pattern throughout all three cities. In this analysis, the three cities have the same general development level, often described as incremental. And the variety of small projects, the result of their incremental histories, is present in all three, at the very highest end of the spectrum of gradual development for large cities globally.

Nevertheless, none of this answers the question of why we can't make cities like this today. The answer, however, is hidden in the phase: They have all evolved over time, with little in the way of planned-use distribution or zoning. Today, almost all planning starts with a projection. This is like mapping out potential future uses with precise planning zones across areas to be developed and includes new cities, redevelopment areas, and pretty much every development, regardless of scale. All planning starts with and is supported by this legal framework and conventions that make changing the process virtually impossible.

Manhattan's legal land-use and zoning plan offers a startling and grim example of how actual development occurred over the past 200 years. This plan shows the increments of use and how development is a clear and compelling representation of an incremental growth pattern. It is a variation of use and an interpretation of building form. It is hard, if not impossible, to walk down any street on the island and think those vast areas were driven by one hand, with one overarching imposition of style, use, and execution. The city was clearly piecemealed together incrementally, against the backdrop of small twenty-five-foot-wide parcels, minuscule increments of subdivision, developed over two centuries. In this sense, it is wholly organic operationally, meaning it grew through thousands of individual decisions about developing separate parcels. Yet, it is also entirely rigid in its plan as an orthogonal framework. Clearly, these two ideas are not mutually exclusive. A city can be both a relentless grid and at the same time 
incremental, or even when defined as an operational process, organic. It doesn't look organic in the way we think of compositional variation, but it is organic in the way it operates.

When the two maps, actual uses and projected (legal) uses, are juxtaposed, the disparity is startling. They provide clarity as to the fundamental difference between the two methods for perceiving and driving the development of cities. They are also grim because they represent, through the projected-use categories, the imposition of a system that legally precludes the emergence of places like Manhattan, or the Marais, the Hamra, the French Concession, Chinon, or the thousands of other wonderful cities and towns from ever being allowed to materialize. Therefore we don't make magnificent cities any longer.

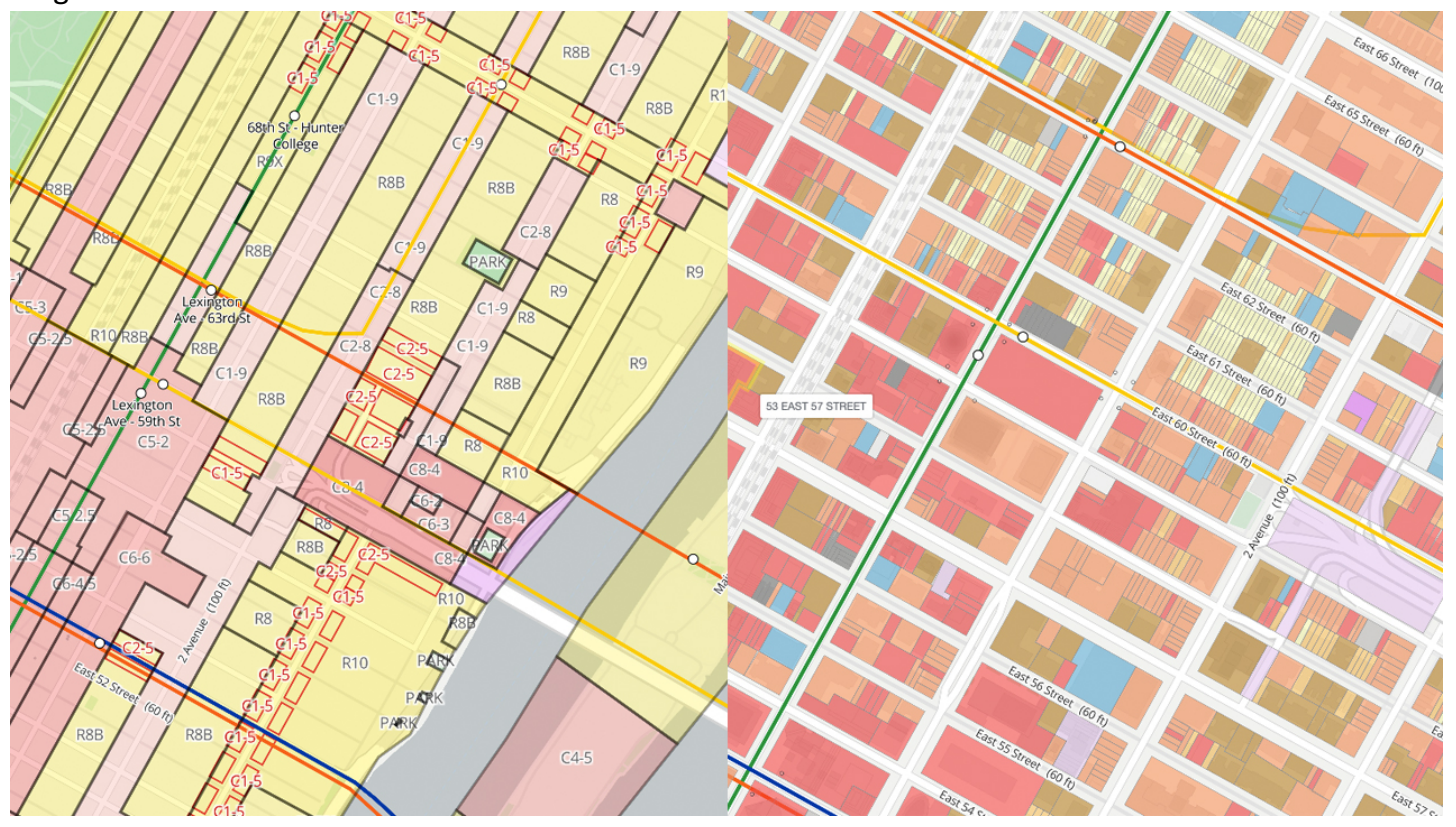

Figure 10 Projected zone use map (left) actual use distribution by parcel (right) (nyc.gov, ZOLA 2020)

Most of the world built today isn't New York, central Paris, or central London, or any of the other wonderful places we find speckling the globe. Most of the world built today comprises dendritic cul-desac suburbs, disconnected business parks, destination retail, lifestyle centers, multifamily clusters, or some variation of all these things. This description is true in the Americas, Europe, Africa, the Middle East, Asia, and Australia. The vast majority of expanding cities, new towns, and redevelopment projects are not planned or designed to be incremental. Instead, they are implementing broad land-use plans that, in most instances, are organic in form, with curved streets, disconnected from their surroundings to ensure singularity of use.

This compositionally organic planning strategy, supported by land-use as the primary element of projecting new development, creates a situation where the operationally organic process that produced places like the Eixample and the Centro Historico in Barcelona is almost impossible to realize. These are places where everything is the same, by and large, and each of these areas is accessed from an arterial, leading to a park where everything is an office or retail or single-family residential or multifamily residential, or industrial. And, of course, most of these places were designed to be organic.

\section{Conclusion}

The regulation and development of cities through broad land-use designations has been the main driver of city planning for almost a century. Because of this, many people in the profession will respond to this 
argument by 1) pointing out positive examples of projects that are incremental, granular in form, or 2) providing examples that seem to argue for land-use separation due to safety issues, such as not putting a slaughterhouse next door to a house. The answer to number one is yes-there are some examples of incremental planning, but they are extremely rare, and even many of those projects that appear to be incremental aren't. The answer to number two is no-you don't want to put a slaughterhouse next to a house, but you do want to put a lot of other things next to that house. This reframes the question that we should be asking ourselves as planners of cities: what are all the things you can (and should) put next to a house?

Unfortunately, until the answer to number one isn't the exception to the rule, and the answer to number two isn't reactionary, we won't be making these incremental, diverse, beautiful places anytime soon.

\section{References}

1961 Zoning Resolution. (1961, December 15). The Zoning Resolution of the City of New York. New York, NY, USA: City of New York.

Allen, D. (2010). The Standard City Planning Enabling Statute and the Regulation of Suburban Block Size. Rocky Mountain Land Use Institute - Sturm College of La. Denver: University of Denver.

Batty, M., Morphet, R., Masucci, P., Stanilov, K. (2014). Entropy, complexity, and spatial information. Journal of Geographical Systems 16, 363-385. doi:10.1007/s10109-014-0202-2

Bridges, W. (1811). Remarks of the Commissioners for Laying Out Streets and Roads in the City of New York, Under the Act of April 3, 1807. Commissioners of Streets and Roads in the City of New York. New York: The City of New York.

Building Zone Resolution. (1916, July 25). Appendix B City of New York Board of Estimate and Apportionment. New York, NY: City of New York.

Christova, P., Scoppa, M., Peponis, J., \& Georgopoulos, A. P. (2012). Exploring Small City Maps. Experimental Brain Research, 223 (2), 207-217.

Jacobs, Jane. (1992) The death and life of great American cities /New York : Vintage Books.

Litman, T. A. (2017). Economic Value of Walkability. Victoria Transport Policy Institute, 1-31. http://www.vtpi.org/walkability.pdf. [Accessed 10.25.17].

Ozbil, A., Peponis, J., \& Stone, B. (2011). Understanding the Link Between Street Connectivity, Land Use and Pedestrian Flows. Urban Design International, 16 (2), 125-141.

Ozbil, A., Yesiltepe, D., Argin, G. (2015). Modeling Walkability: the effects of street design, street-network configuration and land-use on pedestrian movement. ITU A|Z, 12 (3), 189-207.

Peponis, J., Allen, D., French, S., Scoppa, M., \& Brown, J. (2007). Street Connectivity and Urban Density: Spatial Measures and Their Correlationlation. 6th International Space Syntax Symposium.

Peponis, J., Bafna, S., \& Zhang, Z. (2008). The Connectivity of Streets: Reach and Directional Distance. Environment and Planning B: Planning and Design, 35, 881-901.

Peponis, J., Ross, C., \& Rashid, M. (1997). The Structure of Urban Space, Movement and Co-presence: The Case of Atlanta. Geoforum , 28 (3-4), 341-358. 